\title{
Uma genealogia dos enfoques positivos e contribuições normativas no debate econômico sobre meio ambiente
}

\section{A Genealogy of Positive Approaches and Normative Contributions to the Economic Debate on Environment}

\author{
Rosana Icassatti CORAZZA*
}

\begin{abstract}
RESUMO
As agendas de pesquisa em Economia integram fortemente, desde o renascimento do ambientalismo nos anos 1960, questões atinentes à dimensão ambiental. Ao longo das décadas subsequentes, o movimento das ideias econômicas voltadas à temática ambiental não tem de forma alguma se restringido ao mainstream, alcançando grande parte desta pluralidade de tratamentos que convivem e se disputam tanto no campo acadêmico quanto na informação e instrumentalização de políticas. O objetivo deste artigo consiste, em um primeiro momento, na identificação de algumas das abordagens teóricas que têm influenciado a interpretação dos problemas ambientais e que vêm contribuindo para forjar instrumentos para o desenho de policies para sua solução. A seguir, é realizado um exercício com o intuito de elaborar uma genealogia dos enfoques e contribuições que procura retraçar a origem ou a filiação teórica de tratamentos positivos e normativos que se encontram hoje na literatura econômicaque aborda a problemática ambiental.
\end{abstract}

Palavras-chave: economia do meio ambiente; enfoques positivos; contribuições normativas; metodologia.

\begin{abstract}
Since the revival of environmentalism in the $60^{\prime}$ s, research programs in Economics tend intensely to integrate environmental issues. Throughout the subsequent decades, the path of economic ideas about the theme has not been restricted to mainstream contributions, but has also reached a great deal of the profusion of approaches that coexist and are in conflict in the academic arena as well as in the information and implementation of public policies. The purpose of this paper is twofold. Firstly, it focuses on the identification of important theoretical approaches that have influenced the economic explanation of environmental problems and the building of instruments for policy design and implementation. Secondly, it presents an exercise to elaborate a genealogy of approaches and contributions that aims to sketch the origin or theoretical affiliation of positive and normative treatments that are found currently in the economic literature focused on environmental matters.
\end{abstract}

Keywords: environmental economics; positive approaches; normative contributions; methodology.

\footnotetext{
* Doutora em Política Científica e Tecnológica (Unicamp). Professora nas Faculdades de Campinas e Pesquisadora Colaboradora no Departamento de Política Científica e Tecnológica (IG-Unicamp). E-mail: rosanacorazza@gmail.com
} 


\section{Introdução}

Quando a "revolução ambiental" chegou nos anos 60, os economistas já a estavam esperando. A literatura econômica [já] possuía uma visão razoavelmente coerente do problema da poluição e [contava] com um conjunto convincente de suas implicações para a política pública (BAUMOL; OATES, 1988, p. 1).

Em grande medida a partir das reflexões iniciais de biólogos norte-americanos participantes do debate ambientalista dos anos 60 (como Rachel Carson, Garrett Hardin e Paul Ehrlich) e das contribuições dos economistas (como William Baumol e Wallace Oates, que retomam as contribuições de Pigou, dos anos 20) para a política ambiental na década de 70 , questões particulares relativas à proteção do meio ambiente passaram a atingir a esfera pública de forma sistemática e vigorosa, não apenas pela sensibilização do público em geral, mas, sobretudo, por meio da informação e instrumentalização das políticas públicas, em particular, das políticas ambientais.

A divulgação do debate ambientalista, isto é, o domínio de certos aspectos do conteúdo científico do debate ambientalista pelo público leigo, pode parecer trivial às gerações que nasceram depois dos anos 60 ou 70, mas o transbordamento do debate científico sobre causas e consequências da degradação ambiental dos muros da academia para os fóruns públicos é praticamente tão recente quanto essas próprias gerações.

A década de 70 também concentrou um movimento de retomada de conceitos já desenvolvidos anteriormente pela teoria econômica, de reformulação de antigos instrumentos de política ambiental e de concepção de outras ferramentas para operacionalizar a intervenção das autoridades públicas na realidade econômica e ambiental das nações. Uma intensa produção de textos no seio da literatura econômica foi ensejada pela crítica dos economistas aos apologistas do "crescimento zero". ${ }^{1}$ A tônica dos textos escritos nesta década eram a capacidade e a eficiência das ciências econômicas para o enfrentamento da crise ambiental. ${ }^{2}$ Esse movimento pode ser facilmente constatado principalmente em duas áreas de grande produção naquele momento: a que explora o problema dos recursos naturais, através da Economia dos Recursos Naturais; e a que se volta para o problema da poluição, por meio da tradicional Economia do Meio Ambiente.

Desde então, a incorporação da problemática ambiental aos domínios das Ciências Econômicas tem se expandido, abrangendo contribuições tanto das Ciências Naturais, no sentido da compreensão dos problemas ambientais em causa, quanto aportes de outras áreas da própria Economia (como Microeconomia, Organização Industrial, Economia do Setor Público e outras). As contribuições cruzadas entre distintas áreas vão se conformando numa verdadeira malha de relações que explicam desde os recortes dos objetos até as opções metodológicas de modelização, de forma que compreender os rumos do pensamento econômico que exerce influência sobre as políticas ambientais não é tarefa trivial.

Este artigo, de caráter necessariamente propedêutico, é provocativo neste sentido.

Qual olhar devemos lançar sobre os rumos desta fundamentação econômica das políticas ambientais? Quais são as filiações teóricas e as perspectivas metodológicas que subjazem aos enfoques prevalentes? E, ainda, é sempre possível identificar com clareza suas derivações de policy?

Propomos, neste artigo, elaborar algumas reflexões que contribuam para elucidar esses pontos. $\mathrm{O}$ método empregado para tanto consiste em revisões sistemáticas e temáticas da literatura econômica sobre meio ambiente, tendo como enfoque analítico as perspectivas epistemológicas e metodológicas das Ciências Econômicas, balizadas ainda por considerações afeitas à História do Pensamento Econômico contemporâneo.

Para tanto, o artigo está organizado em três seções. Na primeira delas, são apresentadas de forma breve algumas das principais abordagens econômicas sobre regulamentação que exercem influência teórica sobre a

\footnotetext{
${ }^{1}$ A obra que abriu o debate público sobre o tema foi o livro de Meadows et al., Limits to Growth (1972). Cf. também a crítica intitulada "El sindrome del fin del mundo", de 1974, às perspectivas pessimistas da visão dos limites do crescimento nos anos 70, feita por John Maddox, editor da revista britânica Nature.

${ }^{2}$ São exemplos representativos dessa literatura os trabalhos de Baumol e Oates (1971), Solow (1974), Stiglitz (1974) e Simon (1981)
} 
integração da dimensão ambiental pelas análises econômicas. Na segunda seção, é delineado um retrospecto das práticas de política ambiental tendo como foco as progressivas alterações que as levam de uma abordagem de comando-e-controle a uma perspectiva de corregulação. Na terceira seção, propomos um exercício propedêutico de reflexão sobre os rumos da fundamentação teórica das políticas ambientais, a partir de uma genealogia selecionada de alguns dos mais relevantes autores que contribuíram para o debate em questão. Finalmente, na discussão final, retomamos a proposta do artigo e identificamos algumas proposições que, segundo entendemos, permanecem abertas a futuras investigações sobre os caminhos teóricos e metodológicos da abordagem econômica acerca da problemática ambiental.

\section{Interpretações econômicas sobre política ambiental em perspectiva}

Como a temática das recomendações de política ambiental consiste num desdobramento normativo dos mais caros a algumas vertentes das Ciências Econômicas, façamos um pequeno détour por uma síntese de algumas das contribuições nesse campo.
A Economia interpreta a necessidade de regulamentação - ou de intervenção pública - a partir da identificação de certas fontes (causas ou origens) do problema a ser regulamentado. Como em outras áreas da análise econômica, existem divergências entre as escolas de pensamento a respeito das causas do problema e, como também em outras áreas, sobre os remédios para sua solução. Apresentamos, no Quadro 1, uma síntese das interpretações econômicas dos problemas a serem regulamentados.

Este Quadro permite uma visão de conjunto de diferentes escolas de pensamento econômico que, de uma maneira ou de outra, têm contribuído para a recomendação (ou não) da intervenção pública em assuntos diversos. Essas recomendações se alinham ou divergem na acepção do funcionamento do mercado (perfeitamente competitivo), que poderia, segundo a escola de pensamento, ou gerar falhas (de mercado) a serem corrigidas pelo Estado, ou corrigir falhas de regulação.

Lévêque (1998) procura refinar um pouco mais este conhecido tema da análise econômica. De acordo com o autor, é possível encontrar linhas de parentesco e de clivagem entre as quatro escolas de análise econômica indicadas no quadro abaixo.

Segundo o autor, a Escola da Escolha Pública é a antítese da tradicional Economia do Bem-Estar. É pos-

QUADRO 1 - SÍNTESE DAS INTERPRETAÇÕES ECONÔMICAS DA REGULAMENTAÇÃO

\begin{tabular}{|l|l|l|l|l|l|}
\hline Escola & $\begin{array}{l}\text { Autores } \\
\text { selecionados }\end{array}$ & $\begin{array}{l}\text { Causa do } \\
\text { Problema }\end{array}$ & $\begin{array}{l}\text { Finalidade da } \\
\text { Regulamentação }\end{array}$ & $\begin{array}{l}\text { Caracterização do Regu- } \\
\text { lamentador }\end{array}$ & Prescrição \\
\hline $\begin{array}{l}\text { Teoria do Bem- } \\
\text {-Estar (“Abordagem } \\
\text { Convencional” da } \\
\text { Economia do Meio } \\
\text { Ambiente) }\end{array}$ & $\begin{array}{l}\text { Pigou; } \\
\text { Baumol e Oates }\end{array}$ & $\begin{array}{l}\text { Falha de mercado } \\
\text { (externalidades } \\
\text { negativas) }\end{array}$ & $\begin{array}{l}\text { Alocação eficiente } \\
\text { (ótimo de Pareto). }\end{array}$ & $\begin{array}{l}\text { Representante do interesse } \\
\text { geral; onisciente. }\end{array}$ & $\begin{array}{l}\text { Regulamentar em pre- } \\
\text { sença de uma falha de } \\
\text { mercado. }\end{array}$ \\
\hline Escolha Pública & Buchanan & "Mercado político" & Redistribuição. & $\begin{array}{l}\text { Venal; a serviço de grupos } \\
\text { de interesse. }\end{array}$ & $\begin{array}{l}\text { Suprimir a regulamen- } \\
\text { tação. }\end{array}$ \\
\hline Teoria das Incitações & Laffont e Tirole & $\begin{array}{l}\text { Falha de mercado } \\
\text { (informação assi- } \\
\text { métrica) }\end{array}$ & $\begin{array}{l}\text { Alocação eficiente } \\
\text { (second-best). }\end{array}$ & $\begin{array}{l}\text { Constrangido a buscar o } \\
\text { interesse geral e dependente } \\
\text { de informações pertencentes } \\
\text { aos regulamentados. }\end{array}$ & $\begin{array}{l}\text { Regulamentar minimi- } \\
\text { zando as falhas de regu- } \\
\text { lamentação. }\end{array}$ \\
\hline $\begin{array}{l}\text { Nova Economia } \\
\text { Institucional }\end{array}$ & $\begin{array}{l}\text { Coase; } \\
\text { Williamson }\end{array}$ & Custos de transação & $\begin{array}{l}\text { Alocação eficiente de } \\
\text { custo mínimo } \\
\text { (minimização de custos } \\
\text { de produção e de } \\
\text { transação). }\end{array}$ & $\begin{array}{l}\text { Procura minimizar os custos } \\
\text { e é aberto a todas as solu- } \\
\text { ções (compreendido aí o } \\
\text { laisser-faire). }\end{array}$ & $\begin{array}{l}\text { Apenas regulamenta } \\
\text { quando as outras solu- } \\
\text { ções são mais custosas. }\end{array}$ \\
\hline
\end{tabular}

FONTE: Elaboração própria a partir de Lévêque (1998). 
sível observar esta clivagem desde a caracterização do regulamentador (que nesta é portador do interesse geral, enquanto naquela é vestido de interesses próprios e de grupos particulares), até a prescrição última, representada na primeira pela supressão total da regulamentação e na última pela busca da correção das falhas do mercado.

O leitor um pouco familiarizado com o debate econômico sobre o Meio Ambiente reconhecerá nesta última escola a filiação teórica que permite à Economia do Meio Ambiente sugerir a taxação dos recursos ambientais (a "taxa pigouviana") para a internalização dos custos ambientais por parte dos agentes privados.

Lévêque (1998) ressalta que a escola da Teoria das Incitações representa uma espécie de síntese entre Escolha Pública e Teoria do Bem-Estar, no sentido de que se filia a ambas, em alguma medida. Da última, ela empresta o interesse geral que deve guiar a ação pública. Da primeira, ela retoma o reconhecimento dos interesses privados, em particular dos grupos de pressão, que quase inevitavelmente influenciam essa ação. O que permite amalgamar esta dupla filiação é o recurso ao caráter imperfeito e incompleto da informação. É este caráter que "explica a existência de grupos de interesse pela atração de uma renda ligada à informação que eles detêm" ao mesmo tempo em que "explica [...] a margem de ação do regulamentador para satisfazer seus próprios objetivos" (LÉVÊQUE, 1998, p. 21).

A clivagem entre a Teoria das Incitações e a Teoria do Bem-Estar, por sua vez, reside no rebaixamento do ideal de eficiência do ótimo de Pareto, na última, para o da eficiência de second-best, na primeira.

Para tratar da contribuição da Nova Economia Institucionalista, Lévêque (1998) nos chama a atenção para o fato de que, tanto quanto a Escolha Pública, esta escola não se fundamenta na existência de falhas de mercado para propor a regulamentação. A Nova Economia Institucionalista demonstra que, em um mundo em que existem custos de transação, o conceito de falha de mercado não é útil. O que interessa, de acordo com seus tenentes, é o alcance de um "ótimo" que não diz respeito ao referencial paretiano, mas sim a um ótimo que minimize custos (de produção e de transação) - ainda que esta situação signifique abrir mão da própria regulamentação (e, neste caso, a prescrição seria a mesma da Escolha Pública).

$\mathrm{O}$ interesse de se conhecer este quadro geral das contribuições das Ciências Econômicas para o problema geral da regulamentação (ou, no mesmo sentido em que empregamos o termo neste artigo, da regulação ${ }^{3}$ ) é o de compreender como se coaduna a ideia de regulação - conforme prescrita pelos economistas em geral - à resolução dos problemas ambientais.

Já mencionamos anteriormente que as contribuições das Ciências Econômicas neste sentido ganharam grande momento por ocasião dos debates sobre os limites do crescimento, nos anos 70 . Vale a pena retomarmos algumas delas.

A década de 70 concentrou um movimento de retomada de conceitos já desenvolvidos anteriormente pela teoria econômica, de reformulação de antigos instrumentos de política ambiental e de concepção de outras ferramentas para operacionalizar a intervenção das autoridades públicas na realidade econômica e ambiental das nações. Uma intensa produção no âmbito da literatura econômica foi ensejada pela crítica dos economistas aos defensores do crescimento zero. Muitos dos textos escritos nesta década se empenhavam em demonstrar a capacidade e a eficiência das Ciências Econômicas para o enfrentamento da crise ambiental. ${ }^{4}$ Esses textos podem ser agrupados em duas frentes de crítica à ideia dos limites do crescimento: uma frente explora o problema dos recursos naturais, através da Economia dos Recursos Naturais; e outra se volta para o problema da poluição, através da Economia do Meio Ambiente. ${ }^{5}$

\footnotetext{
${ }^{3}$ A língua portuguesa, assim como a francesa, tem a vantagem sobre a língua inglesa de possuir dois termos: regulação e regulamentação. Regulação define o ato ou efeito de regular-se, que diz respeito a sujeitar-se a regras; "autorregular-se" (sic) significa estabelecer as próprias regras. Regulamentação define o ato ou efeito de regulamentar que, por sua vez, significa sujeitar a regulamento. Os franceses, mais precisos, definem regulação como o fenômeno que concorre ao bom funcionamento de um organismo ou de uma economia, onde muitas forças - não raro contraditórias - atuam simultaneamente. Como são conhecidos, a este respeito, os economistas regulacionistas franceses (como Boyer e Aglieta), é importante esclarecer que quando empregamos aqui os termos regulação e autorregulação não estamos fazendo nenhuma referência à chamada Escola Regulacionista. Apenas estamos usando a permissão que nos concede a fluidez do nosso vernáculo para tomar as acepções desses termos como sinônimos de regulamentação e autorregulamentação (que seriam mais caros aos economistas puristas).

${ }^{4}$ Cf., por exemplo, Buchanan e Tullock (1975).

${ }^{5}$ É oportuno lembrar que, pelo menos desde meados dos anos 1980, ambas as disciplinas têm se renovado, seja pela incorporação das dimensões mais complexas dos problemas ambientais transfronteiriços, seja pela integração de novos desenvolvimentos teóricos e metodológicos da própria Ciência Econômica.
} 
Em primeiro lugar, no caso da crítica que explorava o problema dos recursos naturais, talvez a manifestação mais representativa seja a de Solow, que ganhou o Prêmio Nobel de Economia em 1987, justamente por suas contribuições para as teorias de crescimento econômico. Solow publicou, em 1974, na American Economic Review, seu artigo "The economics of resources or the resources of economics", no qual sustenta que a economia dispõe de ferramentas para ultrapassar o obstáculo da insuficiência de recursos para o crescimento econômico. Retomando o arrazoamento do precursor da Economia dos Recursos Naturais, Harold Hotelling, Solow se referia particularmente à eficiência do sistema de preços, desenhado pela mão invisível do mercado, em proporcionar a melhor alocação dos recursos. O autor ainda estava seguro quanto às possibilidades de encontrar substitutos para os materiais na medida em que estes se tornassem raros, posição que marca sua crença na propriedade de ampla substituição entre o que se convencionou chamar de capital natural e o capital feito pelo homem.

Em segundo lugar, quanto ao problema da poluição, a crítica dos economistas do meio ambiente estava fundada no desenvolvimento de uma abordagem particular sobre a natureza dos problemas ambientais e na proposição de instrumentos econômicos de política ambiental para intervenção e correção desses problemas.

De acordo com os economistas filiados à tradicional Economia do Meio Ambiente, a natureza dos problemas ambientais é dada por sua característica externa ao sistema econômico. Ou seja, os problemas ambientais se originam do fato de os chamados bens ambientais não terem preço no mercado. Vale dizer, em outras palavras, que não há mercados para bens como a qualidade do ar ou da água, ou mesmo para certas características de ativos ambientais, como sua beleza paisagística. Embora seja possível que os indivíduos usufruam desses bens, não existem direitos de propriedade bem definidos sobre eles (são os commons, de $\operatorname{Hardin}^{6}$ ). Deriva daí o não cômputo dos custos da utilização dos bens ambientais nos cálculos privados. É por isso que os economistas dizem que os custos ambientais são "externalizados" pelos agentes econômicos. Desde The Economics of Welfare, de Pigou (1920), diz-se, assim, que ocorre uma externalidade negativa, conceito que designa os efeitos negativos da atividade produtiva no meio ambiente, quando os benefícios da utilização dos bens ambientais são apropriados privadamente, enquanto que seus custos são socializados.

Baseado nesta acepção sobre a natureza dos problemas econômicos, a Economia do Meio Ambiente deriva suas proposições de política ambiental na forma de instrumentos de intervenção. O mais conhecido instrumento é a taxação, ou, como também é conhecida, a ecotaxa. ${ }^{7}$ A taxação é, grosso modo, um procedimento que, a partir de cálculos de valoração econômica dos danos ambientais, atribui um valor a ser pago pelo poluidor pela poluição que emite, de acordo com o chamado princípio do poluidor-pagador. ${ }^{8}$

$\mathrm{Na}$ literatura pertinente à tradicional Economia do Meio Ambiente encontram-se muitos exercícios dedicados a comparar esses instrumentos de política ambiental, ditos econômicos, com os instrumentos convencionalmente empregados, ditos de comando-e-controle, principalmente no que diz respeito à sua eficiência econômica e aos seus efeitos sobre a distribuição de renda, a competitividade de firmas e países, a mudança tecnológica etc.

Além da taxação, outros instrumentos econômicos para implementação de políticas ambientais são as permissões negociáveis em mercados, os sistemas de tarifas pela coleta de lixo e os sistemas de consignação conhecidos como embalagens retornáveis (OCDE, 1997). Como exemplos de instrumentos de comando-e-controle, temos as normas e padrões de emissões, como por exemplo, os limites aplicados pelos organismos de controle ambiental a certas indústrias, aplicados para a

\footnotetext{
${ }^{6}$ A referência aqui é o artigo publicado por Garrett Hardin, em 1968, na revista Science, "The tragedy of the commons".

${ }^{7}$ Há ainda outros instrumentos econômicos, como as permissões negociáveis em mercados e os subsídios. Cf. esses e outros instrumentos e uma avaliação sobre seu uso em OCDE (1997).

${ }^{8}$ A valoração econômica, tanto dos ativos ambientais quanto dos danos causados pelas atividades antrópicas ao meio ambiente, desenvolve conceitos e metodologias indispensáveis para o cálculo das ecotaxas e de outros "preços" para bens ambientais. Trata-se de uma área muito dinâmica e com um desenvolvimento muito expressivo nas Ciências Econômicas nas duas últimas décadas.
} 
emissão de gases poluentes, como o gás carbônico ou os óxidos de nitrogênio (OCDE, 1997).

Embora tenham influenciado muito marginalmente as políticas ambientais nos anos 70 , sendo preteridos aos instrumentos convencionais de comando-e-controle, os instrumentos econômicos passam a ter um apelo crescente junto aos formuladores dessas políticas no decorrer das décadas de 80 e de 90 (OCDE, 1997). Eles chegam a ser sugeridos em 1987 pela Comissão Mundial para Meio Ambiente e Desenvolvimento, autora do conhecido livro Nosso futuro comum, como ferramentas fundamentais para o alcance da sustentabilidade do desenvolvimento (CMMAD/ONU, 1991).

Em síntese, o tema da regulação - ou da regulamentação -, além de ser dos mais caros à análise das Ciências Econômicas, tem sido central na discussão sobre os instrumentos de intervenção pública a serem adotados para a implementação de políticas ambientais. Esta discussão tem se dado de forma bastante intensa, opondo os chamados instrumentos econômicos aos de comando-e-controle desde o início da década de 70.

$\mathrm{Na}$ discussão entabulada ao longo deste item, deve causar estranheza a ausência do tratamento das contribuições da heterodoxia, em particular da crescente literatura produzida pelos tenentes da Economia Ecológica e das abordagens ainda um tanto tímidas da Economia Evolucionista. Esta é, aliás, uma crítica que podemos fazer à tipologia proposta por Lévêque (1998). Estas duas escolas serão abordadas, ainda que de forma muito sintética, no terceiro item deste artigo, na forma de uma genealogia selecionada das abordagens teóricas da Economia sobre a problemática ambiental.

Por enquanto, cabe ressaltar que observação das práticas de regulação recentes aplicadas no âmbito das políticas ambientais nos tem evidenciado uma tendência ao emprego de engajamentos voluntários dos agentes regulamentados. O próximo item é dedicado a compreender os rumos recentes dessas práticas nesse sentido.

\section{Da regulamentação pública à perspectiva da corregulação}

Na seção anterior, discutimos algumas das principais abordagens teóricas sobre a regulamentação em
Economia que têm contribuído tanto para a interpretação dos problemas ambientais quanto para a proposição de soluções. Na presente seção, procuraremos compreender a progressão das práticas de regulamentação em matéria de proteção do meio ambiente a partir da explicitação dos vínculos entre tipos de regulação e dos instrumentos de política ambiental sugeridos a cada "momento" no tratamento das políticas ambientais.

Historicamente, os sistemas de regulamentação direta inevitavelmente precedem à incitação econômica, sendo esta a primeira razão pela qual não é possível implementar esta última de maneira "pura". Não há como fazer tábula rasa da política ambiental preexistente e, daí, os sistemas de implementação serão necessariamente híbridos ou mistos, como prefere chamá-los Barde:

[O] imperativo teórico frequentemente levou a se colocar o problema dos instrumentos de política ambiental em termos de substituição da regulamentação direta pela incitação econômica. [...] as taxas não são jamais aplicadas isoladamente e a realidade nos mostra a existência de sistemas mistos, onde as taxas e a regulamentação direta são empregadas não de forma concorrente, mas de modo complementar (BARDE, 1992, p. 286-287).

Tendo em mente que os "tipos puros" de instrumentos, tal como são descritos na literatura teórica, não são encontrados na realidade e reconhecendo, portanto, as limitações da distinção entre regulamentação direta e incitação econômica, manteremos neste artigo o uso desta terminologia por razões essencialmente analíticas.

São identificados quatro momentos na evolução das práticas de política ambiental, observáveis a partir de dois elementos: a abordagem de intervenção predominante e o tipo de instrumento de política ambiental sugerido.

\section{Primeiro momento: a regulamentação direta ou de "comando-e-controle"}

Até a década de 60, aqueles instrumentos existiam apenas nos quadros-negros e nas revistas acadêmicas, como produtos das imaginações férteis dos acadêmicos. (HAHN, 1989, p. 95). 
A regulamentação direta é feita por meio de dois tipos de regras: o quadro regulamentar geral e as normas ambientais.

$\mathrm{O}$ quadro regulamentar geral, como assinalou Barde (1992), engloba as leis e os códigos específicos sobre a água, a poluição atmosférica, o barulho, a pesca, as florestas etc. São diretrizes mais gerais a serem seguidas pelos agentes e que são concebidas e implementadas pelas autoridades ambientais de um país.

As normas ambientais servem como instrumentos de implementação direta de política ambiental porque podem ser associadas diretamente aos objetivos definidos. Por exemplo, se o objetivo é controlar o volume de poluentes em uma determinada região, a norma de qualidade ambiental pode designar exatamente o volume máximo permitido para as emissões em questão. São, além disso, aplicadas de maneira direta aos poluidores pelas agências de proteção ambiental e, por isso, são também conhecidas como instrumentos de comando-e-controle. Essas normas podem ser agrupadas, ainda segundo Barde, em quatro classes: normas de qualidade, normas de emissão, normas de processo e normas de produto.

As normas de qualidade englobam os parâmetros de qualidade ambiental desejáveis aplicados a um meio receptor de maneira geral (atmosfera, corpos de água ou solo), independentemente da origem do poluente. Aí se incluem os limites toleráveis de concentração de certas substâncias no ar, na água ou no solo.

Exemplos de aplicação incluem, conforme assinala Barde (1992), a concentração máxima de nitratos por litro de água, a de dióxido de enxofre $\left(\mathrm{SO}_{2}\right)$ por metro cúbico de ar, o nível máximo de barulho em determinadas localidades.

As normas de emissão são instrumentos de controle ambiental que definem obrigações dos poluidores potenciais quanto aos resultados a serem atingidos. Por meio deste tipo de norma, as autoridades ambientais podem chegar até a interditar completamente a emissão de certos poluentes, proibindo, por exemplo, o uso de determinadas substâncias tóxicas.

Assim, normas de emissão são limites impostos pela autoridade a cada poluidor individualmente. Elas são estabelecidas segundo o tipo de substância: a quantidade de material particulado que pode ser emitida por determinada planta industrial; a quantidade de certos gases para suas emissões gasosas; os níveis de DBO (demanda bioquímica por oxigênio) e de DQO (demanda química por oxigênio) permitidos para seus efluentes líquidos; o volume ou conteúdo em metais pesados para seus resíduos sólidos etc.

As normas de processo se referem ao tipo de tecnologia (de "procedimento de controle") adotada na luta contra a poluição e, por isso, também são chamadas de padrões baseados em tecnologias (technology-based standards). Convencionalmente, elas não dizem respeito ao processo produtivo propriamente dito (que se consubstanciariam em tecnologias "mais limpas"), mas sim a tecnologias de "remediação" da poluição. Pode se tratar, por exemplo, da imposição de um certo equipamento para o tratamento dos efluentes.

Os principais termos empregados na literatura com referência às normas de processo dizem respeito às melhores tecnologias disponíveis para a solução de problemas ambientais (do inglês best available technologies - BAT) e às melhores tecnologias disponíveis não acarretando custos excessivos (do inglês best available technologies not entailing excessive costs - BATNEEC). Ambos os tipos de normas funcionam como instrumentos que direcionam as opções tecnológicas (technology forcing instruments) rumo a alternativas consideradas mais desejáveis pelas autoridades ambientais.

As normas de produto dizem respeito a especificações determinadas pelas autoridades ambientais para certas linhas de produtos. Tais normas podem ser exemplificadas pela limitação dos teores de enxofre e chumbo nos combustíveis, de fosfato nos detergentes, características e tamanho de embalagens para certos produtos etc.

\section{Segundo momento: instrumentalização econômica das políticas ambientais}

Os instrumentos econômicos mais conhecidos ou "clássicos" são: i) a taxação; ii) os subsídios e iii) as permissões negociáveis. Eles são apresentados pelos economistas como alternativas menos custosas que a regulamentação direta e, sob certas condições, mais eficazes. Recentemente, a literatura econômica também passou a analisar os sistemas de depósito. 
Depois da regulamentação direta, de acordo com Barde (1992), a taxação é o mais difundido instrumento de implementação das políticas ambientais.

Taxas são valores pagos pela emissão de determinada quantidade de substâncias poluentes (emissões gasosas, efluentes líquidos, poluição sonora). ${ }^{9} \mathrm{O}$ domínio de aplicação da taxação é bastante amplo, envolvendo desde a gestão de recursos hídricos e a redução de poluição atmosférica até a disposição de resíduos. São muitas as experiências conhecidas de aplicação da taxação como instrumento econômico para gestão ambiental (OCDE, 1997).

Os subsídios são uma classe de instrumentos de política ambiental dos quais o Estado pode lançar mão, participando, desta forma, como observa a OCDE (1997), do financiamento da luta contra a poluição. Assim, no âmbito das políticas ambientais, subsídios são, usualmente, benefícios concedidos pelo Governo a empresas pertencentes a setores da economia que, na falta deste auxílio, enfrentariam dificuldades sérias para suportar os custos da luta contra a degradação ambiental. Este instrumento pode assumir três formas: as subvenções ou subsídios propriamente ditos, os créditos especiais e os incentivos fiscais.

A criação de mercados onde se efetua a negociação de permissões, certificados ou direitos de poluir foi proposta pela primeira vez, segundo Vivien (1994), por John Dales, em 1968. Esta proposição decorre diretamente da noção de que os problemas ambientais têm sua origem na ausência de mercados para negociação dos bens e serviços ambientais, ausência que por sua vez se justifica pela inexistência de direitos de propriedade bem definidos para estes bens e serviços.

As permissões negociáveis constituem, pois, o instrumento que mais se aproxima do "ideal" normativo de correção das externalidades, a mercantilização dos bens e serviços ambientais, pois estão associadas à efetiva criação de um mercado para esses bens/serviços.

As permissões negociáveis (tradable permits), certificados ou direitos de poluir são títulos que confe- rem ao seu proprietário (uma empresa poluidora, por exemplo) o direito de emitir determinado montante de substâncias poluentes (ou de utilizar determinado montante de recursos naturais).

A autoridade ambiental tem o mandato de emitir esses títulos, respeitando o montante permitido, seja para as emissões (no caso da poluição), seja para uso (no caso de exploração de recursos renováveis ou não renováveis). Esses certificados serão negociados em mercados especialmente criados para este fim, sob a supervisão da autoridade ambiental (que, além de emitir, tem o poder de resgatar esses títulos).

Em poucas palavras, num sistema de certificados ou permissões, a autoridade fixa o montante de títulos segundo o nível desejado de poluição (ou exploração de recursos), sendo que o preço desses títulos será estabelecido no mercado pela negociação entre as firmas interessadas em vendê-los ou comprá-los.

Um dos principais argumentos a favor da adoção dos chamados instrumentos econômicos baseia-se em sua teórica "eficiência econômica". Hahn (1989) analisou os resultados práticos da aplicação dos instrumentos prescritos pela análise econômica. Se esses resultados diferiam dos prognósticos feitos pela teoria econômica, isso se devia, segundo o autor, ao fato de que os instrumentos econômicos nunca são aplicados segundo a forma prevista pela teoria. Os instrumentos econômicos são introduzidos, ao invés disso, num sistema de controle ambiental baseado na regulamentação direta:

\footnotetext{
Virtualmente todos os sistemas de regulamentação que aplicam taxas e permissões negociáveis se baseiam no sistema de regulamentação direta preexistente. Este resultado não deveria ser terrivelmente surpreendente. A maior parte desses sistemas não é implementada a partir de uma situação inicial em que nada existia; pelo contrário, eles são enxertados em sistemas de regulamentação nos quais normas e padrões representam papel dominante. (HAHN, 1989, p. 7).
}

\footnotetext{
${ }^{9}$ Partindo de uma análise de equilíbrio parcial e da consideração de que uma alocação eficiente de recursos não poderia ser alcançada na presença de externalidades, a sugestão de Pigou consistia na imposição de uma taxa aos geradores de externalidades negativas (e, de forma análoga, da atribuição de um subsídio aos geradores de uma externalidade positiva).
} 
Terceiro momento: iniciativas voluntárias ou autorregulação

É impossível falar em autorregulação ambiental da indústria sem lembrar o caso do Programa Responsible Care. Este programa é uma ação da indústria química que incentiva as firmas a demonstrarem seus compromissos com a melhoria de seu desempenho em diversos aspectos: proteção da saúde, segurança e meio ambiente. Iniciado no Canadá, o programa tem sido destinado a recuperar a confiança dos consumidores e da opinião pública. $\mathrm{O}$ programa foi iniciado no final dos anos 80 , na sequência dos amplos e conhecidos acidentes de Bhopal (Índia) e da Basileia (Suíça). Não é o caso, neste artigo, de fazer uma apresentação do programa, mas cabe ressaltar - para nossos objetivos - que um componente importante desta ação voluntária diz respeito ao desenvolvimento de um conjunto de indicadores de desempenho ambiental e de sua difusão fora da indústria. Tais indicadores foram concebidos para medir o progresso ambiental alcançado pelas firmas da indústria química.

A ameaça da implementação de uma regulamentação ambiental mais restritiva e a perspectiva de punições para grandes poluidores não são apenas incentivos que podem forçar firmas a adotar um comportamento mais amigável do ponto de vista ambiental. Sob certas circunstâncias, discutidas por Lévêque (1996), as firmas podem assumir uma ação coletiva para fazer frente a um problema ambiental sem a intervenção governamental direta. Elas escolhem voluntariamente tanto os objetivos ambientais quanto os meios para alcançá-los. Quais são estas circunstâncias?

Uma primeira circunstância é a existência de incentivos mercantis (como aqueles representados pelos efeitos na reputação ou nas economias de rede). Como o regulador privado é essencialmente autointeressado, suas ações servem aos interesses das firmas da coalizão e não àqueles de outras partes. Por exemplo, o Responsible Care documenta que os investimentos na redução da poluição são percebidos pelas firmas da indústria química como necessários para fazer face à redução da demanda por seus produtos devido à imagem ruim da indústria.
Uma segunda circunstância que determina o sucesso da autorregulação é a baixa diferenciação dos custos de redução de impacto ambiental entre as firmas. A perspectiva de ganhos relativos enfraquece a manutenção da coalizão e dá espaço ao problema de free-riding. Uma das dificuldades do Programa Responsible Care diz respeito justamente ao fato de que pequenas e médias empresas da indústria química obtêm menores benefícios que suas concorrentes, as grandes firmas multinacionais. Isto se explica pelo fato de serem menos visíveis ao público em geral e às organizações ambientalistas, sendo menos afetadas pela má reputação da indústria. Além disso, elas são menos equipadas com recursos internos dedicados às questões ambientais para implementar o programa e, consequentemente, torna-se mais difícil - quer dizer, custoso - garantir seu comprometimento com as regras da coalizão.

Em síntese, autorregulação pura, ou seja, sem nenhuma intervenção pública, pode ter, segundo o autor, sucesso sob condições muito restritivas, uma vez que requer: (i) incentivos mercantis; (ii) pequeno número de empresas e custos homogêneos de redução de impactos ambientais; (iii) watchdogs organizados (associações ambientalistas) para superar os problemas de falta de credibilidade dos autocompromissos e do comportamento oportunista (free-riding).

\section{Quarto momento: cooperação público-privada ou corregulação}

A corregulação é uma categoria que recupera, segundo Lévêque (1996), os arranjos institucionais em que as autoridades públicas e as firmas reguladas são mais próximas, no sentido de que suas interações são mais frequentes e importantes.

A corregulação seria uma forma híbrida entre a regulação pública e a autorregulação.O que a aproxima da autorregulação é o fato de que é a própria indústria que estabelece o conjunto de medidas a serem adotadas para o alcance das metas ambientais. A corregulação se assemelha à regulação pública no aspecto de que os objetivos ou metas de qualidade ambiental continuam a ser estabelecidos pelas autoridades públicas. ${ }^{10}$

\footnotetext{
${ }^{10}$ Esta definição um tanto restritiva dos arranjos de corregulação não nos deve fazer perder de vista o fato de que, na prática, tanto objetivos como os meios para alcançá-los acabam por ser, em alguma medida, objeto das negociações que caracterizam o processo regulatório.
} 
A figura 1, abaixo, auxilia a compreender as distinções entre autorregulação e corregulação.

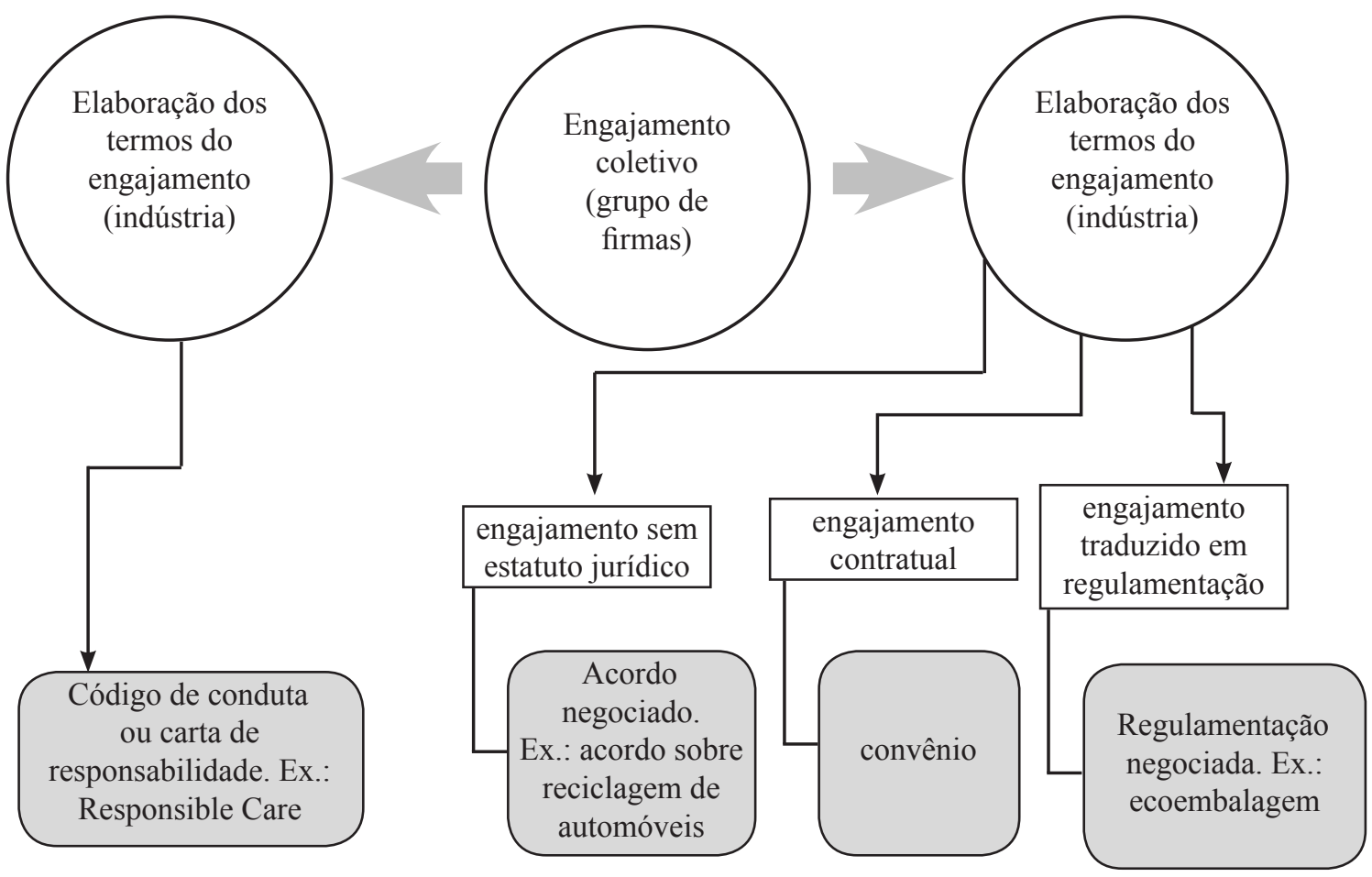

FIGURA 1 - Tipologia dos engajamentos coletivos da indústria. FONTE: Börkey e Glachant (apud FAUCHEUX et al., 1997).

Podemos compreender a emergência deste último momento pelo contexto da evolução das relações que vinculam diversas organizações industriais e as que envolvem essas organizações e os poderes públicos. Essas relações têm se destacado como objeto de análise, seja por sua frequência, seja por envolverem questões ambientais de maneira explícita. Essas relações podem ser chamadas de "engajamentos coletivos" e assumem, segundo Börkey e Glachant (apud FAUCHEUX et al., 1997), quatro formas distintas: código de conduta, acordo voluntário, convênio e regulamentação negociada.

A razão fundamental para tais engajamentos coletivos, segundo Faucheux et al. (1997), é o compartilhamento de custos e de riscos. Do ponto de vista privado, se a incorporação da dimensão ambiental pelas organizações pode implicar custos e riscos, a emergência destas relações externas pode se configurar em oportunidades para a redução destes mesmos custos e riscos.

É necessário, ainda, reconhecer uma dimensão especialmente interessante neste último momento e que diz respeito à conformação das instituições voltadas à concepção e à implementação de políticas ambientais nas diversas esferas regulatórias (internacionais, nacionais e locais). A necessidade de articulação entre essas diversas esferas se coloca na ordem do dia com a emergência dos chamados problemas ambientais globais (como a desertificação, a depleção da camada de ozônio e o aquecimento global). A elaboração de convenções internacionais (como as do clima e da biodiversidade) tem sido o arranjo regulatório adotado em face destes problemas. Nestes arranjos, as articulações entre instâncias públicas e privadas podem ser compreendidas a 
partir de uma abordagem de corregulação. Sobretudo, as articulações entre instituições públicas pertinentes às diversas esferas regulatórias têm tornado esse um campo de policy progressivamente informado pelas contribuições da Nova Economia Institucional. ${ }^{11}$

Tendo caracterizado em breves linhas os "quatro momentos" das práticas de política ambiental, cabe fazer duas observações.

Em primeiro lugar, embora essa sucessão de "momentos" sugira uma "evolução histórica", é preciso atenuar esta perspectiva. De um lado, porque não é nossa intenção sugerir implicitamente uma visão de "evolução" como juízo de valor das formas de regulamentação ambiental. Embora tenham sido realizadas muitas avaliações comparativas entre as formas de regulamentação, não é possível dizer em termos absolutos que alguma é sempre preferível a qualquer outra. De outro lado, porque efetivamente essas diferentes formas de intervenção coexistem no tempo, sendo mais comum a associação entre instrumentos de controle ambiental, como taxas e normas. O que parece acontecer é que, ao longo do tempo, torna-se mais frequente o emprego dos instrumentos econômicos. Da mesma forma, observa-se que mais recentemente as convenções e os acordos têm sido progressivamente adotados. Assim, notamos que temos ao longo do tempo uma transição da regulamentação direta - na qual a intervenção pública no domínio da proteção ambiental se dá de forma independente ou tecnicamente desassistida pelos economistas - para formas de tomada de decisão progressivamente informadas pelos economistas e fundamentadas na teoria econômica.

Em segundo lugar, observamos que nas práticas regulatórias mais recentes o caráter "estratégico" das regulamentações ambientais é reconhecido explicitamente e compreendido a partir de interpretações teóricas. Assim, a interação estratégica - entre grupos, entre regulamentadores e regulamentados, entre grupos de interesse, entre organizações privadas e o poder público - torna-se não apenas um fator para a compreensão do caráter do problema em causa, mas elemento a ser levado em conta na própria construção das soluções, que devem ser "negociadas".

Nesta transição de ideias sobre regulamentação ambiental, convivem e se constroem posições teóricas e metodológicas cujas inter-relações e cujos desenvolvimentos ainda não foram, segundo entendemos, totalmente examinados e discutidos.

Na próxima seção, é feito um exercício provocativo bastante breve no sentido de compreender os rumos do pensamento econômico que exerce influências sobre a interpretação dos problemas ambientais e que instrumentaliza tomadas de decisão no que se refere ao desenho de políticas para solucioná-los.

\section{Proposta de uma genealogia}

[...] the move to market approaches has gathered considerable momentum and substantial further applications can be expected in the next decade. (PEARCE; BRISSON, 1995, p. 25).

De que forma seria possível compreender os rumos do pensamento econômico no tratamento das questões ambientais?

Talvez aqui possamos "reencontrar" algumas das mais intrincadas questões teóricas e metodológicas com que se defrontam os economistas, ao lado de teóricos do conhecimento e de outros pesquisadores desejosos de compreender os caminhos do desenvolvimento da Economia como "Ciência".

No tratamento da "dimensão ambiental", alguns economistas são levados a indagar sobre a forma de relacionamento do "sistema econômico" com o sistema mais amplo em que este se "aninha". Esta tem sido, desde logo, a perspectiva aberta pelas contribuições de Boulding e Georgescu-Roegen e que têm sido amplamente exploradas no âmbito da Economia Ecológica. Também existe uma tendência crescente de tratamento dos sistemas econômicos como "sistemas abertos" com

\footnotetext{
${ }^{11}$ Para uma apresentação da fundamentação teórica e das derivações de policy da Nova Economia Institucional para a problemática ambiental, consultar Paavola e Adger (2002).
} 
tendências auto-organizadoras pelos seguidores de Schumpeter, na linha dos evolucionistas. ${ }^{12}$

Por outro lado, o pensamento do mainstream em matéria de tratamento de questões ambientais, como a tradicional Economia do Meio Ambiente e a Economia dos Recursos Naturais, se mantém amarrado ao isolamento do sistema econômico, abordando os problemas ambientais sob uma ótica estritamente de externalidades estáticas, cuja correção permitiria o retorno a uma situação tão próxima quanto possível da "otimalidade" e da "eficiência econômica".

O objetivo desta seção é justamente tecer algumas considerações a respeito dos rumos do pensamento econômico que baliza as tomadas de decisão em matéria de política ambiental.

Para fornecer uma "matéria" inicial a estas considerações, concebemos, sob a inspiração de Lévêque (1998), Paavola e Adger (2002) e Radzicki (2003), uma "genealogia" das abordagens do pensamento econômico que têm influenciado a interpretação econômica dos problemas ambientais e a concepção de ferramentas de apoio a tomadas de decisão quanto a estes problemas. Esta genealogia selecionada é representada pela figura 2, abaixo.
É evidente que cada “entrada" na Figura 2 não pode ser justificada no âmbito desta seção, dados os limites da proposta e de espaço a que se circunscreve o presente artigo. Optaremos, neste momento, não por elaborar uma interpretação geral desta representação, mas por fazer alguns comentários. Por esta razão, é desnecessário advertir o leitor que se defrontará com uma classificação ainda um tanto arbitrária das escolas.

Observe-se, desta forma, que, enquanto preocupada em cotejar "tipos ideais" de instrumentos, essa arbitrariedade não nos deve impedir de refletir sobre os rumos que vêm tomando as propostas de solução dos problemas ambientais nas mais diversas esferas de tomadas de decisão.

Tendo em mente nossa genealogia selecionada, podemos dizer que a disposição vertical dos autores segue uma disposição temporal aproximada, enquanto que, grosso modo, as escolas de pensamento econômico podem ser alinhadas tanto mais ao lado esquerdo da figura quanto mais near market pode ser considerado o instrumento ou a solução proposta, culminando com o laissez-faire proposto pela Public Choice.

Segundo esta disposição horizontal das escolas, portanto, permitimo-nos considerar que a abordagem

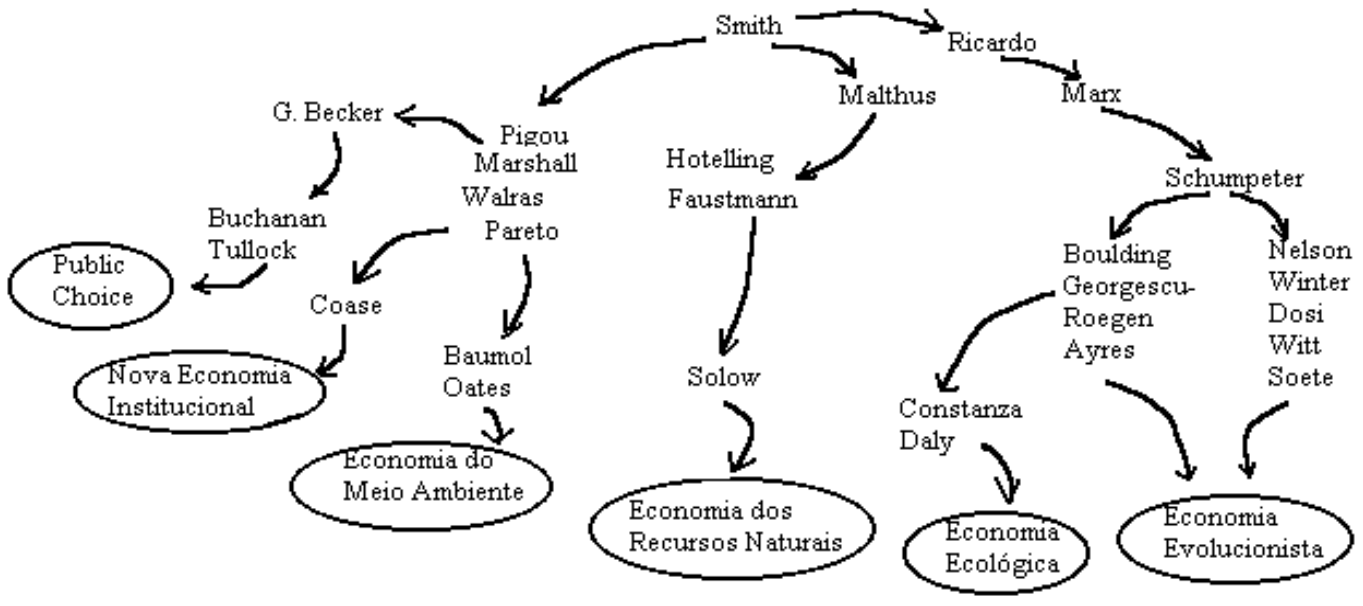

FIGURA 2 - Uma genealogia do pensamento econômico de influência sobre políticas ambientais. FONTE: elaboração própria.

\footnotetext{
${ }^{12}$ A este respeito consultar, por exemplo, Foster (1997) e Hodgson (2001). Tivemos a oportunidade de discutir alguns aspectos desta tendência no último encontro da Sociedade Brasileira de Economia Política. Cf. Corazza e Fracalanza (2004).
} 
da negociação coasiana, no sentido da livre negociação entre poluidor e vítima na ausência de custos de transação (como uma proposta institucionalista ${ }^{13}$ ), pode ser considerada mais near market do que a taxação, conforme sugerido pela Economia do Meio Ambiente.

Este mesmo tipo de consideração não é cabível, entretanto, segundo compreendemos, para a comparação de uma taxa antipoluição à la Pigou e uma taxa de extração de recursos exauríveis. A taxa antipoluição constitui um instrumento de correção de uma externalidade, ou seja, de correção de uma falha de mercado. Esta taxa não poderia ser considerada, entendemos, mais near market do que a escolha de uma taxa de extração de um minério, que seria um instrumento oferecido pela Economia dos Recursos Naturais. No caso dos recursos exauríveis, a alocação temporal "ótima" do recurso será determinada a partir de considerações sobre o futuro, sendo que a taxa de juros utilizada para a tomada de decisão sobre a "intensidade de exploração" de um recurso exaurível será uma espécie de vetor da insegurança e da preferência pelo presente.

Desta forma, a interpretação da figura acima com relação a este critério não deve ser feita nem em termos absolutos, servindo por ora, como afirmamos mais acima, antes para provocar questionamentos do que para classificar as correntes de pensamento.

Por outro lado, gostaríamos de propor que as escolas colocadas mais à direita na figura (Economia Ecológica e Economia Evolucionista) abraçam progressivamente o tratamento dos sistemas econômicos como sistemas abertos, aninhados em sistemas mais abrangentes, incluindo aí os ecossistemas. Nestes casos, muitas vezes as relações de causa e efeito podem não ser perfeitamente conhecidas. Existe espaço para incerteza. Mesmo o conhecimento das variáveis (e mesmo os agentes) intervenientes nos fenômenos é limitado. A interpretação do comportamento de tais sistemas complexos pode apenas ser capturada de forma limitada por modelos dinâmicos e com recurso ao uso de sistemas não lineares.

As escolas que abordam os sistemas econômicos como sistemas fechados se encontram mais à esquerda. Em particular, a tradicional Economia do Meio Ambiente debruça-se de costume sobre problemas cujas relações causais são perfeitamente conhecidas, as variáveis são passíveis de identificação, a coleta de dados possível, seus valores passíveis de mensuração e de descrição por modelos estáticos. O equilíbrio é tido como um resultado possível.

Empreendemos nesta seção uma série de considerações ainda preliminares sobre os rumos do pensamento econômico cujas influências se fazem sentir no tratamento econômico da problemática ambiental. Nas considerações finais, pontuaremos algumas questões centrais para a compreensão desses rumos que, segundo entendemos, permanecem abertas.

\section{Considerações finais}

O tema geral da discussão proposta neste artigo pertence ao debate econômico acerca da problemática ambiental.

Pudemos, ao longo deste trabalho, demonstrar um movimento que leva as práticas de política ambiental de uma abordagem de regulamentação direta, alheia às contribuições econômicas, ao uso progressivo das ferramentas de implementação de política ambiental "desenhadas" pelas contribuições dos economistas, como as taxas e os certificados negociáveis. Mais ainda, reconhecemos a ampla disseminação recente dos acordos voluntários assinados entre poluidores e o poder público.

Sugerimos que ainda há pouca reflexão sobre os rumos do pensamento teórico em Economia que têm exercido influência sobre as práticas de política ambiental.

Para incitar discussões ulteriores neste sentido, concebemos uma genealogia dos autores de influência sobre o debate econômico a respeito da problemática ambiental e tecemos algumas considerações a respeito do rumo de suas respectivas contribuições.

É preciso reconhecer aqui que o alcance deste exercício ainda foi bastante limitado, dada sua natureza explicitamente propedêutica e provocativa.

Cabe, neste momento, identificar algumas questões que em nossa opinião permanecem abertas a reflexões sobre os caminhos teóricos e metodológicos da abordagem econômica acerca da problemática ambiental.

\footnotetext{
${ }^{13}$ Nem sempre é evidente relacionar um instrumento de política ambiental a uma escola. Para uma compreensão mais ampla da negociação como proposta "institucionalista" de instrumento de política ambiental, consultar Glachant (1996).
} 
Em primeiro lugar, reconhecemos serem necessárias investigações sistemáticas e discussões mais amplas com respeito à genealogia proposta, com o objetivo de complementá-la, corrigi-la e eventualmente questioná-la ou refutá-la. É preciso, entendemos, desvendar e explicar a malha de relações de filiação e de contribuições cruzadas entre as diferentes abordagens teóricas.

Em segundo lugar, parece sempre haver lugar para discussões com respeito à possibilidade de filiar as derivações normativas às interpretações teóricas. Nem sempre é possível relacionar univocamente um instrumento a uma escola.

Em terceiro lugar, seria necessário questionar e esclarecer de modo fundamentado as possíveis convergências e clivagens epistemológicas entre as escolas.

Não nos parecem triviais estas questões. Nem tampouco nos parecem de interesse exclusivamente teórico

\section{Referências}

BARDE, J-P. (1992). Economie et politique de l'environnement. Paris: Presses Universitaires de France, 1992.

BAUMOL, W.J.; OATES, W.E. The use of standards and prices for protection of the environment. Swedish Journal of Economics, v. 73, n. 1, p. 42-54, 1971.

; _ . The theory of environmental policy. Cambridge: Cambridge University Press, 1988.

BUCHANAN, J. M.; TULlOCK, G. Polluters' Profit and Political Response: Direct Control versus Taxes. The American Economic Review, v. 65, n. 1, p. 139-147, 1975.

CMMAD/ONU. Nosso futuro comum. 2. ed. Rio de Janeiro: Fundação Getúlio Vargas, 1991.

CORAZZA, R. I.; FRACALANZA, P. S. Sistemas abertos em economia: não-linearidade e formalização a partir de contribuições da abordagem evolucionista da mudança tecnológica. In: ENCONTRO NACIONAL DE ECONOMIA POLÍTICA, 9., 2004. Uberlândia: UFU. Disponível em: <http://www.sep. org.br/>.

FAUCHEUX, S.; HAAKE, J.; NICOLAÏ, I. Implications de la mondialisation économique sur la relation environnemententerprises. Rapport de Recherche: C3ED/DGAD/SRAE n. 95285, 1997. ou acadêmico. Num momento de grande difusão do uso dos instrumentos econômicos de política ambiental, ao tomador de decisões também deve interessar uma discussão desta natureza, que lhe permita se posicionar frente ao debate sobre as "usinas" que forjam suas "ferramentas de trabalho".

\section{Agradecimentos}

A autora agradece aos dois pareceristas anônimos e ao revisor da Revista Desenvolvimento e Meio Ambiente, pelas leituras e sugestões. Reconhecimento especial à Fundação de Amparo à Pesquisa do Estado de São Paulo (FAPESP) pelo auxílio financeiro no âmbito do Programa FAP-Livros. Eventuais erros e omissões são da exclusiva responsabilidade da autora.
FOSTER, J. The analytical foundations of evolutionary economics: from biological analogy to economic self-organization. Structural Change and Economic Dynamics, v. 8, p. 427-451, 1997.

GLACHANT, M. Efficacité des politiques environnementales et coûts d'information: une approche coasienne. Thèse (Doctorat) - Ecole Nationale Supérieure de Mines de Paris/ CERNA. Paris, 1996.

HAHN, R. W. Economic Prescriptions for Environmental Problems: how the patient followed the doctor's orders. Journal of Economic Perspectives, v. 3, n. 2, p. 95-114, 1989.

HODGSON, G. M. Darwinism in economics: from analogy to ontology. Journal of Evolutionary Economics, v. 12, p. 259-281, 2001.

LÉVÊQUE, F. Environmental policy in Europe: industry, competition and the policy process. Cheltenham, UK: Edward Elgar, 1996.

.Économie de la réglementation. Paris: La Découverte, 1998.

OCDE. Évaluer les instruments économiques des politiques de l'environnement. Paris: Les Éditions de l'OCDE, 1997. 
PAAVOLA, J.; ADGER, W. N. New Institutional Economics and the Environment: conceptual foundations and policy. CSERGE Working Paper EDM 02-06, 2002. Disponível em: <http://www.uea.ac.uk/env/cserge/publications/wp/ edm/\#2002>. Acesso em: janeiro de 2004.

PEARCE, D.; BRISSON, I. BATNEEC: the economics of technology-based environmental standards with a UK case. Oxford Review of Economic Policy, v. 9, n. 4, p. 24-40, 1995.

RADZICKI, M. J. Mr. Hamilton, Mr. Forrester, and a Foundation of Evolutionary Economics. Journal of Economic Issues, v. 37, n. 1, p. 133-173, 2003.
SIMON, J. The Ultimate Resource. Princeton, NJ: Princeton University Press, 1981.

SOLOW, R. M. The economics of resources or the resources of economics. American Economic Review, v. 64, n. 2, p. 1-14, May 1974.

STIGLITZ, J. E. Growth with Exhaustible Natural Resources. Review of Economic Studies, v. 42 (Symposium), p. 122-152, 1974.

VIVIEN, F-D. Economie et Ecologie. Paris: La Découverte, 1994.

Recebido em 28 de maio de 2012.

Aceito em 28 de julho de 2012.

Publicado em dezembro de 2012. 